CARNELOSSI, M.A.G.; YAGUIU, P.; REINOSO, A.C.L.; ALMEIDA, G.R.O.; LIRA, M.L.; SILVA, F.G.; JALALI, V.R.R. Determinação das etapas do processamento mínimo de quiabo. Horticultura Brasileira, Brasília, v.23, n.4, p.970-975, out-dez 2005.

\title{
Determinação das etapas do processamento mínimo de quiabo
}

\author{
Marcelo Augusto G. Carnelossi; Paula Yaguiu; Anita Caroline L. Reinoso; Gláucia Regina de O. Almeida; \\ Moema L. Lira; Gabriel Francisco da Silva; Vahideh R.R. Jalali
}

UFS, Depto. Eng. Química, Av. Marechal Rondon, s/n, Campus Universitário, Jardim Rosa Elze, 49100-000 São Cristóvão-SE; E-mail: carnelossi@ufs.br

\section{RESUMO}

Este trabalho teve como objetivo estabelecer um fluxograma operacional para o processamento mínimo de quiabo, produto muito consumido e produzido em diversos estados brasileiros. Para isso, foram avaliados dois modelos de fluxograma. Os procedimentos ideais para cada etapa do processamento mínimo foram determinados utilizando os seguintes parâmetros: tipos de corte, concentração do sanitizante, enxágüe (tratamento com ácido), tempo de centrifugação e tipo de embalagem (PEAD a vácuo e bandejas de poliestireno recobertas com filme de PVC, armazenadas em câmara fria $\left(5 \pm 2^{\circ} \mathrm{C}\right)$ por oito dias). Com base na análise sensorial, quiabo cortado em rodelas com aproximadamente $2 \mathrm{~cm}$ de espessura mostrou-se o mais aceito. Dentre as concentrações de sanitizantes avaliadas, o tratamento com concentrações de $100 \mathrm{mg} \mathrm{L}^{-1}$ de cloro ativo durante 10 minutos, mostrou eficiência significativa na redução de coliformes totais, aeróbios mesófilos e fungos e leveduras. A utilização do ácido cítrico (1\%) durante o enxágüe mostrou-se eficiente na retirada da mucilagem do produto e verificou-se ainda que o tempo para centrifugação de quiabo deve ser de 10 minutos. A embalagem de PEAD a vácuo foi a que melhor preservou a qualidade dos produtos. Para o processamento mínimo de quiabo deve ser utilizado o seguinte fluxograma: recepção, seleção, lavagem, corte, sanitização, enxágüe com ácido, centrifugação, embalagem e armazenamento.

Palavras-Chave: Abelmoschus esculentus (L.) Moench, sanitização, centrifugação, embalagens, conservação.

\begin{abstract}
Determination of the stages of minimum processing of okra

This work aimed to establish an operational flowchart for the minimum processing of okra, a product much consumed and produced in diverse Brazilian States. In this work two models of flowchart were evaluated. The ideal procedures for each stage of the minimum processing were determined by utilization of the following parameters: types of cut, concentration of the rinse (treatment with acid), time of centrifugation and type of the packing (PEAD the recovered polystyrene vacuum and trays with film of PVC, stored in cold chamber $\left(5 \pm 2^{\circ} \mathrm{C}\right)$ during eight days). On the basis of the sensorial evaluation, okra cuts with approximately $2 \mathrm{~cm}$ of thickness were more accepted. Among the concentrations of sanitization products, the treatment with concentrations of $100 \mathrm{mg} \mathrm{L}^{-1}$ of active chlorine during 10 minutes showed significant efficiency in the reduction of total coliforms, mesophiles aerobic, molds and yeast. The citric acid (1\%) used during rinses, revealed themselves efficient in the withdrawal of the mucilaginous juice of immature pods. The time for okra centrifugation must be of 10 minutes. The PEAD packing with vacuum preserved the better quality of the minimum processing product. For the minimum processing of okra the following flowchart must be used: reception, selection, washing, cut, sanitization, rinse with acid, centrifugation, packing and storage.
\end{abstract}

Keywords: Abelmoschus esculentus (L.) Moench, sanitization, centrifugation, packaging, storage.

\section{(Recebido para publicação em 1 de março de 2005 e aceito em 3 de agosto de 2005)}

$\mathrm{O}$ quiabo (Abelmoschus esculentus (L.) Moench), originário da África, pertencente à família Malvaceae é tradicionalmente cultivado em regiões tropicais. O cultivo dessa hortaliça é bastante difundido na região nordeste do Brasil, por possuir um clima bastante favorável para o seu desenvolvimento (SILVA, 2004).

A comercialização de quiabo é feita, geralmente utilizando-se frutos in natura. Alguns trabalhos têm sido realizados de forma a desenvolver processos de secagem e determinar as propriedades físicas do quiabo (ADOM et al., 1996; AKAR; AYDIN, 2005). No entanto, pesquisas relativas ao processamento mínimo dessa hortaliça ainda são inexistentes, o que faz desse trabalho um marco no desenvolvimento de tecnologia, apresentando uma nova forma de comercialização e agregação de valor a esses produtos.

Em geral, hortaliças minimamente processadas, segundo Moretti (2004), são tecidos vegetais que foram danificados de maneira proposital e que devem ser mantidos na forma fresca e com qualidade por períodos prolongados de tempo, pois esse processo acarreta várias alterações físicas e fisiológicas que afetam a viabilidade e a qualidade dos produtos.

Vários aspectos devem ser considerados quando se trabalha com produtos minimamente processados. Os processos metabólicos relacionados aos estresses sofridos pelos tecidos vegetais como a indução do metabolismo de compostos fenólicos, o escurecimento enzimático e a formação de anaerobiose conduzem, na maioria das vezes, a alterações sensoriais importantes (MORETTI, 2004).

Cantwell (1992) e Vitti et al. (2003) citam que a injúria mecânica causada pelo corte ou descascamento é um dos maiores obstáculos para a conservação dos produtos minimamente processados, apresentando aumento da taxa respiratória na ordem de 3 a 5 vezes, quando comparado aos órgãos intactos. Assim, o armazenamento do produto em baixas temperaturas torna-se imprescindível, desde o preparo até a comercialização, visando a redução da respiração e preservação da qualidade e da vida de prateleira do produto pré-processado (VITTI et al., 2003).

A utilização de embalagens e de temperaturas adequadas pode manter o pro- 
duto livre de microorganismos patogênicos, com maior manutenção da sua qualidade e uma maior vida de prateleira. As embalagens atuam como barreira protetora, minimizando a perda de água, reduzindo a taxa respiratória durante o armazenamento, bem como facilitando o transporte, manipulação e a venda dos mesmos (CARNELOSSI et al., 2002). A escolha da embalagem para os minimamente processados depende de fatores como a permeabilidade da embalagem a gases, o tipo de produto e sua taxa respiratória, temperatura de armazenamento dentre outros, visando o aumento do tempo de vida de prateleira (SCHLIMME; ROONEY, 1994).

O objetivo do trabalho foi estabelecer o fluxograma para o processamento mínimo do quiabo, levando-se em consideração o tipo de corte, a concentração do sanitizante, tratamento com ácido para a redução da mucilagem, tempo de centrifugação, tipo de embalagem e temperatura de armazenamento.

\section{MATERIAL E MÉTODOS}

O experimento foi desenvolvido no laboratório de tecnologia de alimentos da UFS. O quiabo utilizado foi adquirido na Associação de Produtores Orgânicos do Agreste (ASPOAGRE), localizada no município de Itabaiana (SE), onde foram transportados em sacolas plásticas para o laboratório e mantidos em temperatura ambiente $\left( \pm 25^{\circ} \mathrm{C}\right)$.

Os fluxogramas avaliados foram a) Recepção - Seleção - Lavagem Sanitização - Corte - Embalagem e b) Recepção - Seleção - Lavagem - Corte - Sanitização - Enxágüe Centrifugação - Embalagem.

Tendo em vista a semelhança das etapas inicias entre os dois fluxogramas, a recepção, a seleção e lavagem foram realizadas da mesma forma para todo material. A recepção do quiabo foi realizada colocando-se os frutos em caixas plásticas em ambiente refrigerado $\left(12^{\circ} \mathrm{C}\right)$ por aproximadamente duas horas. Após esse período os frutos foram retirados da refrigeração e submetidos à seleção e lavagem. Durante a seleção foram escolhidos os frutos que se apresentavam íntegros e sem injurias mecânicas. A lavagem foi realizada utilizan- do-se água corrente para retirada da sujidade. Após a lavagem, para o fluxograma $\mathrm{A}$, os frutos foram submetidos à sanitização e posteriormente aos cortes, e para o fluxograma $\mathrm{B}$, os frutos foram submetidos ao corte.

O corte dos frutos foi realizado manualmente com o auxílio de facas de aço inox, afiadas e previamente higienizadas em solução de cloro $\left(100 \mathrm{mg} \mathrm{L}^{-1}\right)$. Os quiabos foram cortados de três formas, rodelas de aproximadamente $2 \mathrm{~cm}$, picados em cubos com $\pm 0,5 \mathrm{~cm}^{3}$ e cortados longitudinalmente em $\pm 10 \mathrm{~cm}$.

Para a etapa da sanitização, amostras de quiabo, tanto inteiras quanto cortadas, foram imersas em soluções de cloro ativo de marca comercial Sumaveg (Diversey-Lever), com concentrações de $50 \mathrm{mg} \mathrm{L}^{-1}, 100 \mathrm{mg} \mathrm{L}^{-1} \mathrm{e}$ $150 \mathrm{mg} \mathrm{L}^{-1}$, por $10 \mathrm{~min}$. Durante as etapas de sanitização e corte, nove amostras de $25 \mathrm{~g}$ foram retiradas para serem submetidas à análise microbiológica, de forma a determinar bactérias aeróbias mesófilas, coliformes totais, bolores e leveduras.

Para o fluxograma A, após a sanitização, o produto foi cortado e embalado em bandejas de poliestireno recobertas com filme PVC. Para o fluxograma B, após a etapa da sanitização, os quiabos cortados foram enxaguados em soluções contendo quatro níveis de ácido cítrico $(0,5 ; 1,0 ; 1,5$ e 2,0\%) por 10 minutos. Enxágüe sem ácido foi utilizado como controle ( $3 \mathrm{mg} \mathrm{L}^{-1}$ de cloro ativo), visando a retirada do excesso de mucilagem aderido no quiabo.

Testes de centrifugação foram realizados em centrífuga industrial, com velocidade angular de $1290 x g$, por períodos de $2 ; 3 ; 5 ; 7$ e 10 min.

Amostras de $200 \mathrm{~g}$ foram armazenadas em dois tipos de embalagem: bandejas de poliestireno recobertas com PVC e em embalagens de polietileno de alta densidade (PEAD) a vácuo, e armazenadas a temperatura de $5^{\circ} \mathrm{C} \pm 2^{\circ} \mathrm{C}$, por oito dias.

A cada dois dias, foram realizadas análises dos teores de vitamina $\mathrm{C}$, acidez total, pH e coloração (intensidade de escurecimento) do produto armazenado.

Os teores de vitamina $\mathrm{C}$ foram determinados utilizando a metodologia proposta pela American Official Analysis of Chemistry (AOAC, 39.051) (CARNELOSSI et al., 2002).

$\mathrm{O} \mathrm{pH}$ foi determinado em $\mathrm{pH}$ metro digital da marca Schott em $50 \mathrm{ml}$ de solução obtida pela homogeneização e filtragem de 5,0 $\mathrm{g}$ da amostra em água destilada.

A acidez total (AT) foi determinada utilizando-se $10 \mathrm{ml}$ da solução utilizada para a determinação do $\mathrm{pH}$, adicionando-se o indicador fenolftaleína a $1 \%$, e titulado com $\mathrm{NaOH}(0,1 \mathrm{~N})$. A AT foi expressa em \% de ácido cítrico.

$\mathrm{O}$ índice de escurecimento do produto foi acompanhado utilizando-se um colorímetro (Minolta CR-10), calibrado com a cor branca. Para as medições, foram retiradas 3 rodelas de quiabo de cada repetição, e as leituras foram realizadas na parte interna e externa do produto. Os parâmetros obtidos, L, que indica luminosidade (claro/escuro); a, que indica a cromaticidade no eixo da cor verde (-) para vermelha (+); e b, que indica a cromaticidade no eixo da cor azul (-) para amarela (+), foram utilizados para calcular o índice de escurecimento (IE) de acordo com Palou et al. (1999): IE= [I100(x-0,31)I/0,172], em que, $x=(a+1,75 \mathrm{~L}) /(5,645 \mathrm{~L}+\mathrm{a}-$ 3,012b).

A análise sensorial foi realizada utilizando o Teste de Aceitabilidade, com escala hedônica de 9 pontos $(9=$ gostei extremamente, 5 = indiferente e 1 = desgostei extremamente). Foram entrevistadas 30 pessoas não treinadas que avaliaram o produto quanto à preferência em relação ao tipo de corte apresentado.

A microbiota contaminante dos produtos foi avaliada por meio da determinação da contagem padrão de bactérias aeróbias mesófilas, bolores e leveduras e a presença de coliformes totais, segundo a metodologia proposta por Vanderzant e Splittstoesser (1992). As análises foram efetuadas em porções de $25 \mathrm{~g}$ do material vegetal homogeneizado com $225 \mathrm{ml}$ de água peptonada a $0,1 \%$. A contagem padrão de aeróbios mesófilos foi feita em Ágar Padrão para Contagem (PCA), após incubação a 30$32^{\circ} \mathrm{C}$ por 24 a $48 \mathrm{~h}$. Coliformes totais foram determinados pela técnica do Número Mais Provável (NMP), utilizando-se Caldo Lauril Sulfato Triptose para 
Tabela 1. Análises microbiológicas do quiabo minimamente processado submetida a diferentes tratamentos de corte e sanitização. São Cristóvão (SE), UFS, 2004.

\begin{tabular}{lccc}
\hline Amostra & $\begin{array}{c}\text { Bactérias aeróbias } \\
\text { mesófilas }^{1}\end{array}$ & Bolores e leveduras & Coliformes totais \\
\hline Matéria prima & $6.5 \times 10^{4}$ & $1.9 \times 10^{3}$ & $>110$ \\
Inteiro s/sanit. & $6.4 \times 10^{4}$ & $4.3 \times 10^{4}$ & $>110$ \\
Inteiro 50ppm & $3.3 \times 10^{4}$ & $8.1 \times 10^{2}$ & 15 \\
Inteiro 100ppm & $3 \times 10^{3}$ & $4.4 \times 10^{2}$ & 2.8 \\
Inteiro 150ppm & $3 \times 104$ & $*$ & 3.5 \\
Cortado s/sanit. & $4.9 \times 10^{2}$ & $5.1 \times 10^{2}$ & 5.3 \\
Cortado 50ppm & $3 \times 10^{3}$ & $*$ & 5.3 \\
Cortado 100ppm & $*$ & $*$ & 9.3 \\
Cortado 150ppm & $4.3 \times 10^{2}$ & $*$ & 9.3 \\
\hline
\end{tabular}

${ }^{1}$ valores na ordem de $10^{2}$ a $10^{4} \mathrm{UFC/g}$ na contagem padrão.

*inferior ao limite $\left(<2,5 \times 10^{2}\right)$

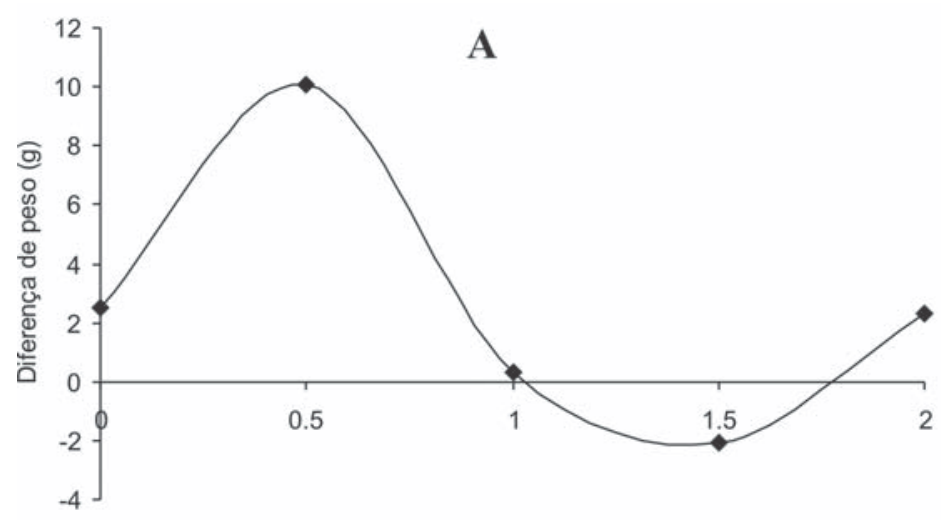

Concentração de a.citrico (\%)

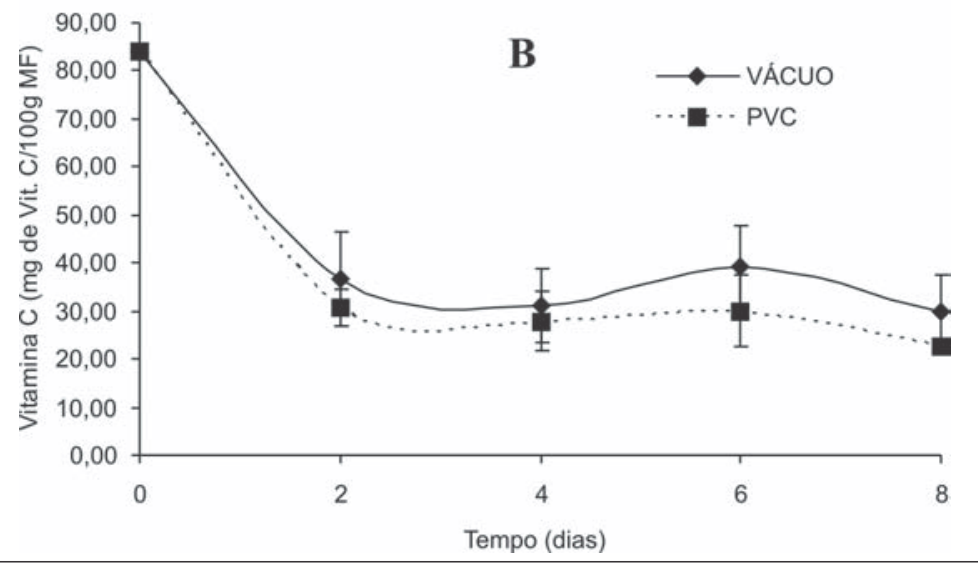

Figura 1. Diferença de peso (A) de quiabo minimamente processado tratado com diferentes concentrações de ácido cítrico no enxágüe e centrifugados por 10 minutos, e teores de vitamina C (B) do quiabo embalado a vácuo e em bandejas com PVC, armazenados a $5 \pm 2{ }^{\circ} \mathrm{C}$ por 8 dias. As barras representam o erro padrão da média. São Cristóvão (SE), UFS, 2004.

o teste presuntivo e Caldo Bile Verde Brilhante, para o confirmativo. A contagem de bolores e leveduras, foi realizada inoculando-se $0,1 \mathrm{ml}$ de cada amostra em 15 a $20 \mathrm{ml}$ do meio de cul- fatorial $2 \times 5$ (dois tipos de embalagem e 5 períodos de avaliação). Foram utilizadas 3 repetições com aproximadamente $200 \mathrm{~g}$ do produto em cada embalagem. Os resultados foram submetidos à análise de variância pelo teste $\mathrm{F}$ e comparação de médias pelo teste Tukey (5\%), com o auxílio do software Assistat (Assistência Estatística), versão 7.2 beta.

\section{RESULTADOS E DISCUSSÃO}

Por meio de análises microbiológicas, observou-se que a concentração de $50 \mathrm{mg} \mathrm{L}^{-1}$ mostrou-se eficiente no controle dos coliformes totais, reduzindo-se os valores de $120 \mathrm{NMP} \mathrm{g}^{-1} \mathrm{ml}^{-1} \mathrm{da}$ matéria-prima para 5,3 $\mathrm{NMP} \mathrm{g}^{-1} \mathrm{ml}^{-1} \mathrm{no}$ produto cortado e sanitizado (Tabela 1). Para o controle dos fungos, leveduras, bactérias aeróbias e mesófilas, a concentração de $100 \mathrm{mg} \mathrm{L}^{-1}$ foi mais eficiente, apresentando valores abaixo do limite de contagem. Nas amostras sanitizadas inteiras e depois cortadas (fluxograma A), observou-se que, apesar da concentração de 50 a $100 \mathrm{mg} \mathrm{L}^{-1}$ de cloro ter apresentado eficiência no controle dos microorganismos, a manipulação (corte) do produto após a sanitização ocasionou uma recontaminação da amostra, inviabilizando, dessa forma, a utilização desse fluxograma. De acordo com Pilon (2003), a lavagem de hortaliças com 50 $\mathrm{mg} \mathrm{L}^{-1}$ de cloro livre na água reduz significativamente a contagem total de aeróbios mesófilos, enquanto que os coliformes fecais mostraram-se mais sensíveis ao cloro não sendo detectados após lavagem com 10, 20 e $50 \mathrm{mg} \mathrm{L}^{-1}$.

Os resultados obtidos por meio do teste de aceitabilidade determinaram que o corte no formato de rodelas $(2 \mathrm{~cm})$ foi o mais aceito, apresentando nota média de 6,9, correspondente ao termo da escala hedônica "gostei moderadamente". Os cortes no formato longitudinal e picado não diferiram estatisticamente entre si, apresentando notas 5,7 (indiferente) e 6,1 (gostei ligeiramente), respectivamente.

A utilização de $1 \%$ de ácido cítrico na etapa de enxágüe (Figura 1A), associado à centrifugação por $10 \mathrm{~min}$, mostrou-se ideal para a retirada do excesso de água e de mucilagem. Observou-se também que, para o tratamento contro- 
Determinação das etapas do processamento mínimo de quiabo

le, a diferença de peso foi menor do que a da concentração de $0,5 \%$ (Figura 1A). Isso se deve ao fato de que o tempo de centrifugação utilizado para essa amostra, 20 min, não foi suficiente para a retirada do excesso de água e mucilagem aderida ao produto.

A mucilagem encontrada no quiabo é classificada como polissacarídica-ácida associada com proteínas (AMAYAFARFAN et al., 2003), podendo, se não removida, servir de substrato para o crescimento de microrganismos durante o armazenamento, causando a depreciação do produto. Pineli (2004) cita que o ácido cítrico é o principal ácido orgânico de frutas e vegetais, atuando sinergisticamente com ácidos ascórbico e eritórbico e seus sais neutros. É capaz de complexar prooxidantes, como o cobre do centro ativo da polifenoloxidase, inativando-os.

Após o segundo dia de armazenamento, observou-se que os teores de vitamina C (Figura 1B) apresentaram redução de aproximadamente $45 \%$, quando comparados ao quiabo antes do processamento, nas duas embalagens testadas. Esse acentuado decréscimo pode ter sido ocasionado pelo aumento na taxa do metabolismo, causado pela injúria mecânica (corte) da hortaliça, que provoca a oxidação de vários compostos, dentre eles, a vitamina C. (CARNELOSSI et al., 2002).

Após esse período, verificou-se estabilização dos teores de vitamina $\mathrm{C}$. Isso pode ser explicado devido à redução do metabolismo, influenciado pela utilização da embalagem e pelo armazenamento em baixa temperatura $\left(5^{\circ} \mathrm{C}\right)$, como ocorre em diversos produtos minimamente processados (CARNELOSSI et al., 2002). Quando embalados com PVC, verificou-se um decréscimo do teor de vitamina $\mathrm{C}$, comparado com a embalagem a vácuo o que pode, provavelmente, estar associado à alta permeabilidade do filme, que não é capaz de reter o metabolismo do produto.

De acordo com Pilon (2003), a vitamina $\mathrm{C}$ é a mais instável das vitaminas por ser sensível aos agentes físico-químicos como a luz, oxigênio e o calor. Klein (1987) cita que a perda de sua estabilidade pode ser consequiência de vários fatores, como o rompimento ce-

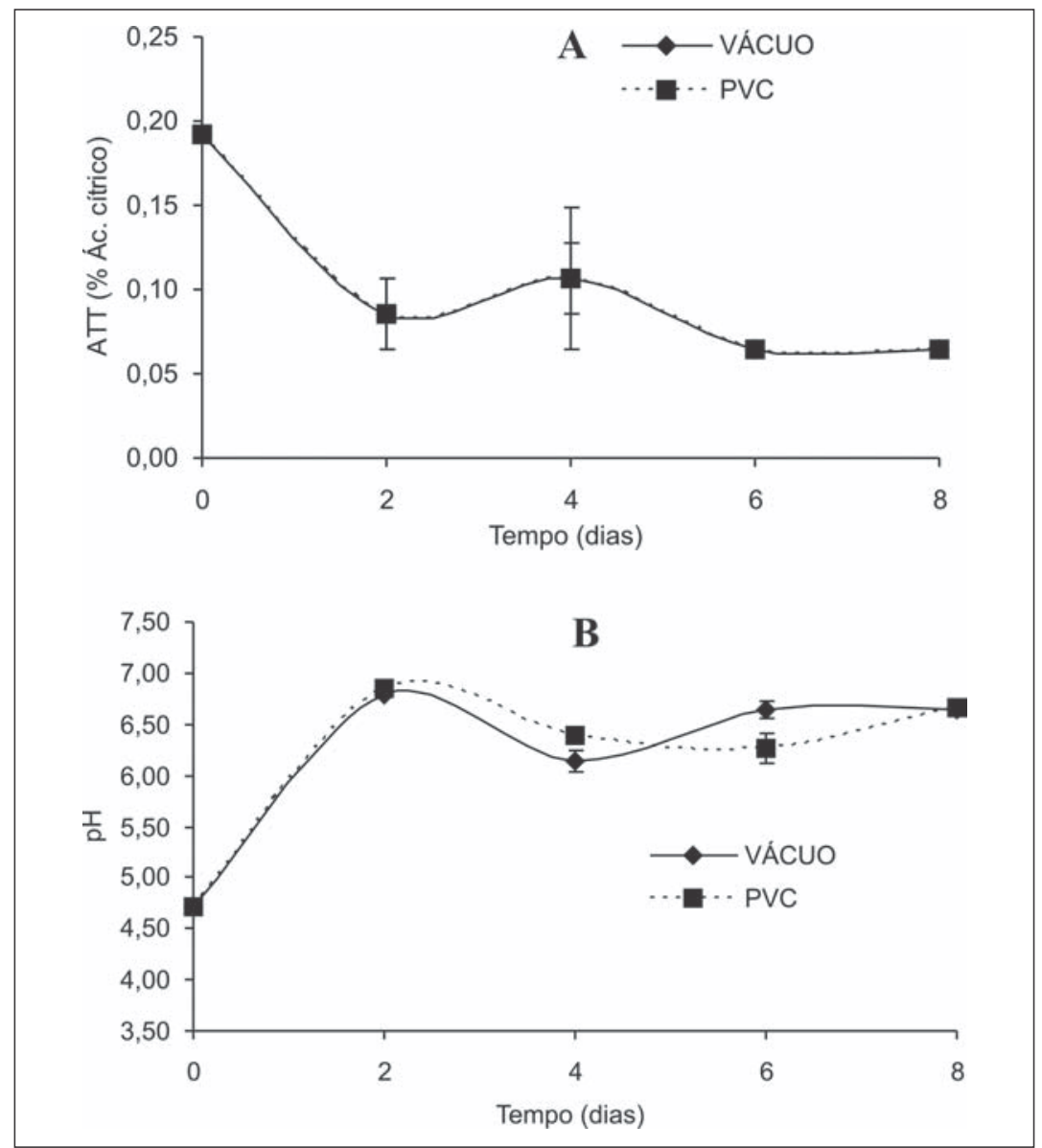

Figura 2. Teores de Acidez Titulável (A) e variação do $\mathrm{pH}$ (B) do quiabo embalado a vácuo e em bandejas com PVC, armazenados a $5 \pm 2^{\circ} \mathrm{C}$. As barras representam o erro padrão da média. São Cristóvão (SE), UFS, 2004.

lular por dano ao tecido, corte ou moedura.

Em todos os tratamentos, verificouse uma queda brusca no segundo dia de armazenamento no teor de acidez titulável (AT) (Figura 2A), após o qual manteve-se constante até o final do experimento, para as duas embalagens testadas.

O controle da atmosfera através da utilização de embalagens e a diminuição da temperatura de armazenamento podem, possivelmente, ter ocasionado a diminuição na taxa de degradação do substrato (açúcares) e, consequentemente, uma provável redução do valor da acidez.

Quanto aos valores do $\mathrm{pH}$ (Figura 2B), observados durante o período de armazenamento, notou-se comportamento inversamente proporcional à acidez, apresentando aumento acentuado no tempo 2 e estabilização até o oitavo dia. Esse resultado pode estar relacionado, com a estabilização metabólica do produto, em virtude da utilização da embalagem e do armazenamento em baixa temperatura.

A intensidade de escurecimento (IE) indicou que a embalagem a vácuo foi eficiente em evitar o escurecimento, tanto na parte interna quanto na parte externa do quiabo (Figuras 3A e 3B). Para a embalagem de PVC, observou-se que a maior permeabilidade da mesma ao oxigênio pode ter provocado o escurecimento do produto, pois o mesmo é utilizado pela enzima polifenoloxidase (PPO) para oxidação de compostos fenólicos (WHITAKER; LEE, 1995).

Em couve minimamente processada, Carnelossi et al. (2002) mostraram que o escurecimento pode estar diretamente relacionado com a atividade da enzima polifenoloxidase, que oxida 


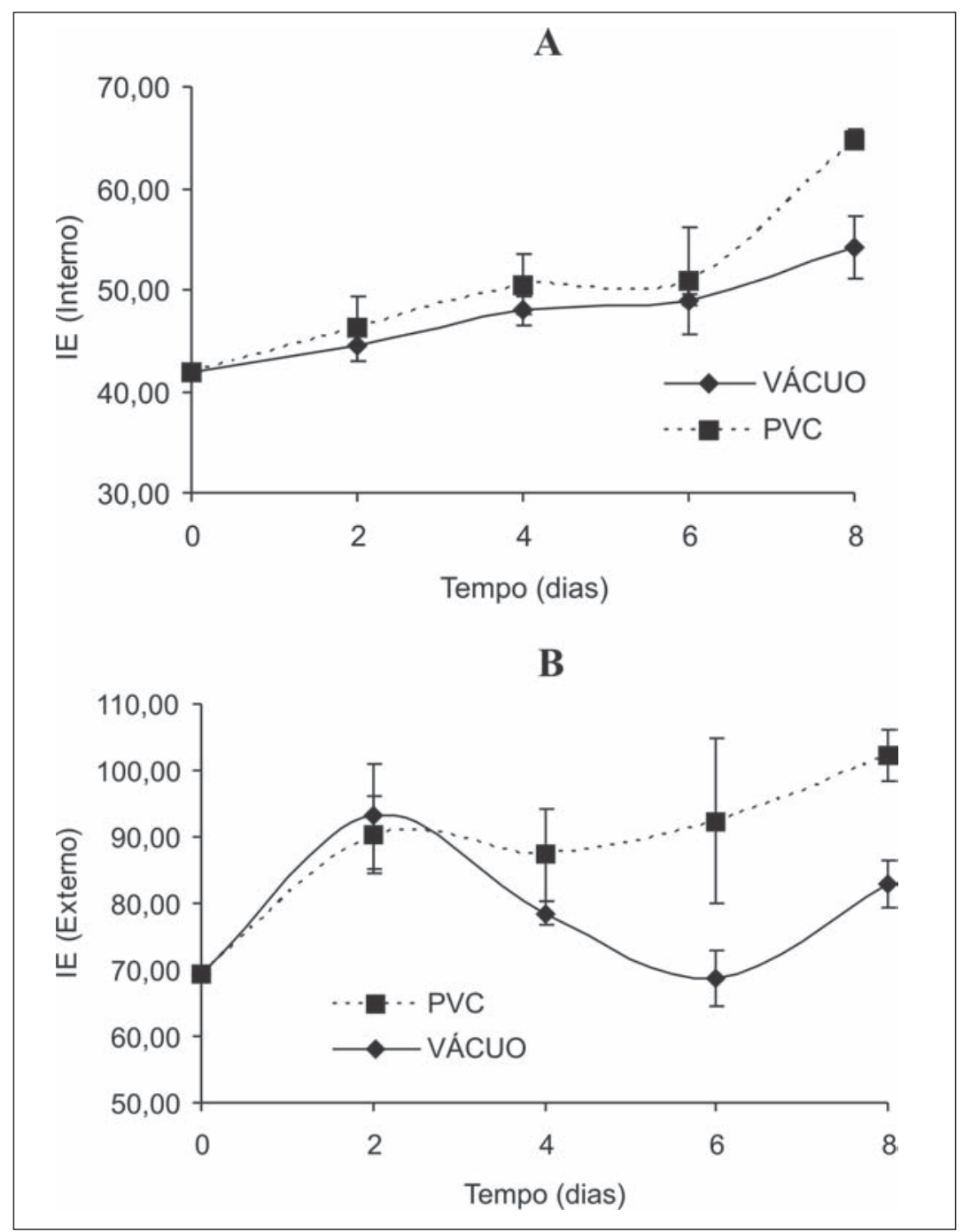

Figura 3. Intensidade de escurecimento (IE) da parte interna (A) e da parte externa (B), de quiabo embalado a vácuo e em bandejas com PVC, armazenados a $5 \pm 2^{\circ} \mathrm{C}$. As barras representam o erro padrão da média. São Cristóvão (SE), UFS, 2004.

compostos fenólicos produzindo uma coloração escura nos tecidos minimamente processados tais como observado em alface e repolho (COUTURE et al., 1993; HOWARD et al., 1994). Moretti et al. (2002) citam que os danos mecânicos (corte) causados durante o processamento podem aumentar a concentração de dióxido de carbono, etileno e de água livre, causar alterações no sabor e aroma, além de aumentar a atividade de enzimas relacionadas ao escurecimento enzimático, como a fenilalanina amônia liase (PAL) e a polifenoloxidase (PPO). Para Goupy et al. (1995), a intensidade do escurecimento enzimático depende de xograma: Recepção - Seleção - Lavagem - Corte (rodelas de $2 \mathrm{~cm}$ ) - Sanitização (100 $\mathrm{mg} \mathrm{L}^{-1}$ de cloro ativo) - Enxágüe (ácido cítrico 1\%) - Centrifugação (10 min) - Embalagem (PEAD a vácuo) Armazenamento $\left(5^{\circ} \mathrm{C}\right)$.

\section{AGRADECIMENTOS}

Os autores expressam seus agradecimentos ao CNPq (Conselho Nacional de Desenvolvimento Científico e Tecnológico), pelo auxílio financeiro concedido para a realização do trabalho, à EMDAGRO e a ASPOAGRE pelo fornecimento do material utilizado nos experimentos.

\section{LITERATURA CITADA}

ADOM, K.K.; DZOGBEFIA, V.P.; ELLIS, W.O.; SIMPSON, B.K. Solar drying of okra - effects of selected package materials on storage stability. Food Research International, v.29, n.7, p.589-593. 1996.

AKAR, R.; AYDIN, C. Some physical properties of gumbo fruit varieties. Journal of Food Engineering, n.66, p.387-393, 2005.

AMAYA-FARFAN, J.; SILVA, V.S.N.; SOUZA, A.S.; PACHECO, M.T.B. Caracterização química parcial da mucilagem do quiabo (Hibiscus esculentus L.) In: SIMPÓSIO LATINO-AMERICANO DE CIÊNCIA DE ALIMENTOS, 5, 2003, Campinas. Anais...Campinas-SP: UNICAMP, 2003.

CANTWELL, M. Postharvest handling systems: minimally processed fruits and vegetables. In: KADER, A.A. (Ed.). Phostharvest technology of horticultural crops. 2ed. Daves: Univ. California, Division of horticulture and natural resources, 1992. p.277-81.

CARNELOSSI, M.A.G.; SILVA, E.O.; CAMPOS, R.S.; SOARES, N.F.F.; MINIM, V.P.R.; PUSCHMANN, R. Conservação de folhas de couve minimamente processadas. Revista Brasileira de Produtos Agroindustriais. UFPB. Campina Grande, v.4, n.2, 2002, p.149-155.

COUTURE, R., CANTWELl, M.I., KE, D., SALTVEIT JUNIOR., M.E. Physiological attributes related to quality attributes and storage life of minimally processed lettuce. HortScience, v.28, n.7, p.723-5, 1993.

GOUPY, P., AMIOT, M.J., RICHARD-FORGET, F., DUPRAT, F., AUBERT, S., NICOLAS, J. Enzymatic browning of model solutions and apple phenolic extracts by apple polyphenoloxidase. Journal of Food Science, v.60, n.3, p.497-501. 1995.

HOWARD, L.R., GRIFFIN, L.E., LEE, Y. Steam treatment of minimally processed carrots sticks to control surface discoloration. Journal of Food Science, v.59, n.2, p.356-8. 1994.

KLEIN, B.P. Nutritional consequences of minimal processing of fruits and vegetables. Journal of Food Quality, v.10, p.179-93, 1987. 
MORETTI, C.L.; ARAÚJO, A.L.; MAROUELLI W.A.; SILVA, W.L.C. Respiratory activity and browning of minimally processed sweet potatoes. Horticultura Brasileira, Brasília, v.20, n.3, p.497500, 2002.

MORETTI, C.L. Panorama do processamento mínimo de hortaliças. In: ENCONTRO NACIONAL SOBRE PROCESSAMENTO MÍNIMO DE FRUTAS E HORTALIÇAS, 3, 2004, Viçosa. Anais... Viçosa: UFV, 2004. p.1-8.

PALOU, E.; LÓPES-MALO, A.; BARBOSACÁNOVAS, G.V.; WELTI-CHAVES, J.

SWANSON, B.G. Polyphenoloxidase activity and color of blanched and high hydrostatic pressure treated banana puree. Journal of Food Science. v.64, n.1, p.42-45, 1999.
PILON, L. Estabelecimento da útil de hortaliças minimamente processadas sob atmosfera modificada e refrigeração. 2003. 111 f. (Tese mestrado) - USP, ESALQ, Piracicaba.

PINELI, L.L.O. Processamento mínimo de batata. In: ENCONTRO NACIONAL SOBRE PROCESSAMENTO MÍNIMO DE FRUTAS E HORTALIÇAS, 3, 2004, Viçosa. Anais... Viçosa: UFV, 2004. p.71-81.

SCHLIMME, D.V., ROONEY, M.L. Packing of minimally processed fruits and vegetables. In: WILEY, R.C.(Ed.). Minimally processed refrigerated fruits \& vegetables. London: Chapman \& Hall. 1994. p.135-82.
SILVA, C.V. Melhoramento Genético do Quiabei ro. Disponível em: <http://www.ufv.br/dbg/ bioano01/div11.htm>. Consultado em: 09 ago. 2004 VANDERZANT, C; SPLITTSTOESSER, D.F. Compendium of Methods for the Microbiological Examination of Foods. American Public Health Association, Washington, 1992.

VITTI, M.C.D.; KLUGE, R.A.; YAMAMOTTO, L.K.; JACOMINO, A.P. Comportamento da beterraba minimamente processada em diferente espessuras de corte. Horticultura Brasileira, Brasília, v.21, n.4, p.623-626, 2003.

WHITAKER, J.R., LEE, C.Y. Recent advances in chemistry of enzymatic browning: an overview. In: LEE, C.Y., WHITAKER, J.R. (Eds.) Enzymatic browing and its prevention. Washington, D.C., ACS, 1995. p.2-7. 